\title{
Effect of alloying elements on magnesium alloy damping capacities at room temperature
}

\author{
Di-qing Wan ${ }^{1)}$, Ying-lin $H u^{1)}$, Shu-ting Ye ${ }^{1)}$, Zhu-min $\mathrm{Li}^{1)}$, Li-li $\mathrm{Li}^{1)}$, and Yi Huang ${ }^{2)}$ \\ 1) School of Materials Science and Engineering, East China Jiaotong University, Nanchang 330013, China
}

2) Materials Research Group, Faculty of Engineering and the Environment, University of Southampton, Southampton SO17 1 BJ, UK

(Received: 15 August 2018; revised: 12 November 2018; accepted: 30 November 2018)

Corresponding author: Di-qing Wan E-mail: divadwan@163.com

\begin{abstract}
Alloying is a good approach to increasing its strength but leads to a reduction of damping to pure magnesium. Classifying the alloying characteristics of various alloying elements in magnesium alloys and their combined effects on the damping and mechanical properties of magnesium alloys is important. In this paper, the properties of the $\mathrm{Mg}-0.6 \mathrm{wt} \% \mathrm{X}$ binary alloys were analyzed through strength measurements and dynamic mechanical analysis. The effects of foreign atoms on solid-solution strengthening and dislocation damping were studied comprehensively. The effect of solid solubility on damping capacity can be considered from two perspectives: the effect of single solid-solution atoms on the damping capacities of the alloy, and the effect of solubility on the damping capacities of the alloy. The results provide significant information that is useful in developing high-strength, high-damping magnesium alloys. This study will provide scientific guidance regarding the development of new types of damping magnesium alloys.
\end{abstract}

Keywords: magnesium alloys; high-damping; high-strength; alloying

\section{Introduction}

Pure magnesium exhibits an excellent damping capacity but cannot be used as a structural material because of its low strength [1]. Materials used as high-damping engineering structural materials must exhibit both good damping capacity and high strength [2-3]. Normally, the characteristics of the material (e.g., alloying elements, secondary phases, and grain size) can improve strength while 
simultaneously influencing damping capacity. Solid-solution treatment and aging precipitation affect the solute concentration distribution and the secondary-phase in the alloy, resulting in changes to dislocation pinning, thereby affecting the damping capacities of the alloy [4-5]. In addition, the damping capacities of magnesium alloys are correlated to the strain amplitude according to the dislocation damping theory of Granato and Lücke [6-7]. Thus, magnesium-based damping alloys are promising high-specific-strength, high-damping structural materials.

Researchers have studied damping magnesium alloys for decades; however, research on highstrength, high-damping alloys are still fragmented and lack depth and systematicity due to the special traits of damping magnesium alloys. The amount of dissolved solute atoms in the matrix can strongly affect the damping capacities of the alloy. At the solute content given herein, the selected alloying elements are solid-solution alloying elements, which can be dissolved into the matrix to form a solid-solution alloy. Some alloying elements undergo eutectic or peritectic reactions with magnesium, which ultimately results in low solubility in the matrix. The addition of this type of alloying element will result in lower damping properties of the alloy because of the presence of more solid-solution atoms. However, elements such as $\mathrm{Al}, \mathrm{Zn}, \mathrm{Ca}$, etc. can be used as alloying elements in magnesium alloys, where they are known to enhance the mechanical properties of the resulting alloys [8-14]. For example, $\mathrm{Al}$ can improve the strength and plasticity of the alloy and improve the structure of its oxide film [8-9]; the solid solubility of zinc in magnesium is high and decreases dramatically with decreasing temperature, which can cause solid-solution strengthening and aging strengthening of the alloy [10-11].

However, previous investigations of cast magnesium alloys with excellent damping and mechanical properties via addition of alloying elements have not achieved good results. Therefore, scientific guidance by determining the alloying characteristics of various elements and their comprehensive effects on the damping and mechanical properties of the resulting materials is necessary for the development of new cast magnesium alloys.

\section{Experimental}

Several $\mathrm{Mg}-0.6 \mathrm{wt} \% \mathrm{X}$ binary alloys were prepared by melting pure $\mathrm{Mg}, \mathrm{Ca}, \mathrm{Al}$, and $\mathrm{Zn}$, as well as $\mathrm{Mg}-30 \mathrm{wt} \% \mathrm{Mn}, \mathrm{Mg}-30 \mathrm{wt} \% \mathrm{Nd}$, and $\mathrm{Mg}-30 \mathrm{wt} \% \mathrm{Y}$ master alloys under $\mathrm{CO}_{2} / 0.5 \mathrm{vol} \% \mathrm{SF}_{6}$ at $700^{\circ} \mathrm{C}$ 
in an arc-melting furnace. The melt was degassed, poured into a steel mold that had been preheated to $300^{\circ} \mathrm{C}$, and cooled under $\mathrm{CO}_{2} / 0.5 \mathrm{vol} \% \mathrm{SF}_{6}$. All samples of the alloy were cut from the castings measuring $140 \mathrm{~mm} \times 30 \mathrm{~mm} \times 30 \mathrm{~mm}$. Rectangular bending beam specimens with dimensions of $50 \mathrm{~mm} \times 5 \mathrm{~mm} \times 1 \mathrm{~mm}$ were machined for damping measurements using the electric-spark cutting method. The damping capacity was determined via $\tan \phi$ (The tangent of the loss angle of the strain lags behind the stress) [15]. Mechanical spectroscopy measurements were carried out using a dynamic mechanical analyzer (Mettler Toledo DMA/SDTA861, Switzerland). The strain-dependent spectrum was recorded at a measurement frequency of $1 \mathrm{~Hz}$ and at various maximum strains from $4 \times 10^{-6}$ to $4 \times 10^{-4}$ at room temperature. Tensile tests were performed at $(25 \pm 0.5)^{\circ} \mathrm{C}$ using an tensile testing machine (Instron 1121, Britain) at a crosshead speed of $1 \mathrm{~mm} / \mathrm{min}$ with a gauge length of $50 \mathrm{~mm}$ and a cross-sectional area of $15 \mathrm{~mm} \times 3 \mathrm{~mm}$. The greatest test force was set to $100 \mathrm{kN}$. To accurately measure the tensile strength, we tested three tensile test samples using the same process and reported the average value. The chemical compositions of the Mg- $0.6 \mathrm{wt} \% \mathrm{X}$ binary alloys were analyzed via inductively coupled plasma spectrometry (ICP).

\section{Results and discussion}

\subsection{Results}

The damping capacities of magnesium alloys are known to be correlated to their strain amplitudes [16-17], where high-damping magnesium alloys commonly exhibit greater damping at lower strain amplitudes. Materials are generally considered to be high-damping when their damping values are greater than 0.01 . The strain amplitude can indirectly reflect the damping capacities of magnesium alloys with damping values of 0.01 . In alloy materials, the number of solute atoms in the matrix strongly affects the damping capacity of the alloy.

Fig. 1 shows the relationship between the damping capacities and strain amplitudes of some binary magnesium alloys at room temperature, clearly demonstrating the influence of alloying elements on the damping capacities of magnesium alloys. The addition of alloying elements with high solid solubilities results in relatively low alloy damping capacities. Therefore, alloying elements with low solid solubilities in magnesium should be prioritized in the preparation of high-damping magnesium alloys. 
In addition, Fig. 1 shows that the effects of various alloying elements on damping capacities differ for solid-solution-type elements at the same concentrations. By contrast, the negative effect of the solid solubility of $\mathrm{Zn}$ on the damping capacities of magnesium alloys is much greater than that of Mn.

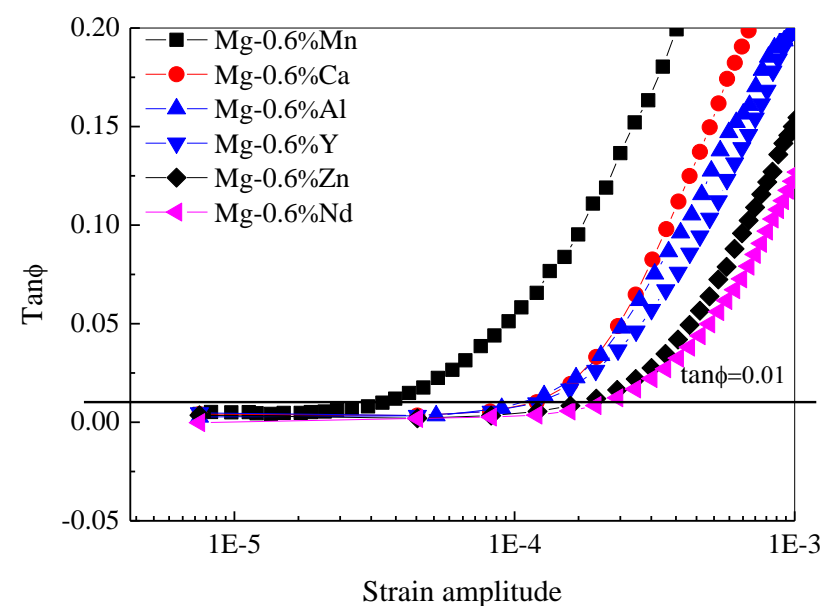

Fig. 1. Relationship between strain amplitude and damping capacity of binary Mgl0.6wt\% X magnesium alloys.

The effects of various alloying elements on the mechanical properties of magnesium alloys are discussed. Table 1 lists the mechanical properties of magnesium alloys after alloying elements were added at low concentrations. The results confirm that alloys that contain $\mathrm{Zn}$ or $\mathrm{Al}$ exhibit good overall mechanical properties. Alloys with elements such as $\mathrm{Mn}, \mathrm{Y}, \mathrm{Nd}$ and $\mathrm{Ca}$ exhibit improved properties but are not as good as those with $\mathrm{Al}$ or $\mathrm{Zn}$. The mechanical properties of magnesium alloys intended for engineering applications can benefit from fine-grain strengthening and secondary-phase strengthening methods, as well as from alloying elements. With regard to the mechanism, solid-solution strengthening and fine-grain strengthening benefit from the dual roles of the solute elements. Thus, the strengthening mechanism includes solute-atom-based and fine-grain strengthening during alloy solidification. On the basis of the aforementioned damping capacity analysis, Al can improve the mechanical properties of the alloy but can also impart the alloy with good damping performance at the same time.

Table 1. Mechanical properties of the investigated binary magnesium alloys

\begin{tabular}{lllll}
\hline Alloy & Phase component & $\sigma_{\mathrm{b}} / \mathrm{MPa}$ & $\sigma_{0.2} / \mathrm{MPa}$ & $\delta / \%$ \\
\hline $\mathrm{Mg}-0.6 \mathrm{wt} \% \mathrm{Al}$ & $\alpha-\mathrm{Mg}$ & 181.7 & 56.7 & 23.7 \\
$\mathrm{Mg}-0.6 \mathrm{wt} \% \mathrm{Y}$ & $\alpha-\mathrm{Mg}$ & 98.7 & 49.9 & 10.9
\end{tabular}




\begin{tabular}{ccccc}
$\mathrm{Mg}-0.6 \mathrm{wt} \% \mathrm{Nd}$ & $\alpha-\mathrm{Mg}$ & 94.3 & 46.3 & 10.9 \\
$\mathrm{Mg}-0.6 \mathrm{wt} \% \mathrm{Mn}$ & $\alpha-\mathrm{Mg}$ & 122.2 & 48.9 & 11.9 \\
$\mathrm{Mg}-0.6 \mathrm{wt} \% \mathrm{Zn}$ & $\alpha-\mathrm{Mg}$ & 138.6 & 50.3 & 14.8 \\
$\mathrm{Mg}-0.6 \mathrm{wt} \% \mathrm{Ca}$ & $\alpha-\mathrm{Mg}$ & 91.9 & 67.0 & 2.2 \\
\hline
\end{tabular}

Note: $\sigma_{\mathrm{b}}$-Tensile strength; $\sigma_{0.2}$-Yield strength; $\delta$-Elongation at break of alloys.

\subsection{Discussion}

\subsubsection{Solid-solution strengthening theory of magnesium alloys}

In general, the hardness and strengths of solid solutions are higher than that of the matrix. The strengthening effect of the substitutional solid-solution usually increases with increasing solute atomic concentration and increasing size difference between the solute and solvent atoms. This enhancement effect is well known as solid-solution strengthening [18-19]. Solid-solution strengthening occurs because of interactions between solute atoms and dislocations. These interactions can be elastic, chemical, or electrical, but elastic interactions between solute atoms and dislocations are most important. In terms of the micromechanism of solid-solution strengthening, various air masses can be formed by the segregation of solute atoms or the solute atoms can be distributed irregularly in the matrix. In both cases, the matrix of the metal material can be strengthened. 


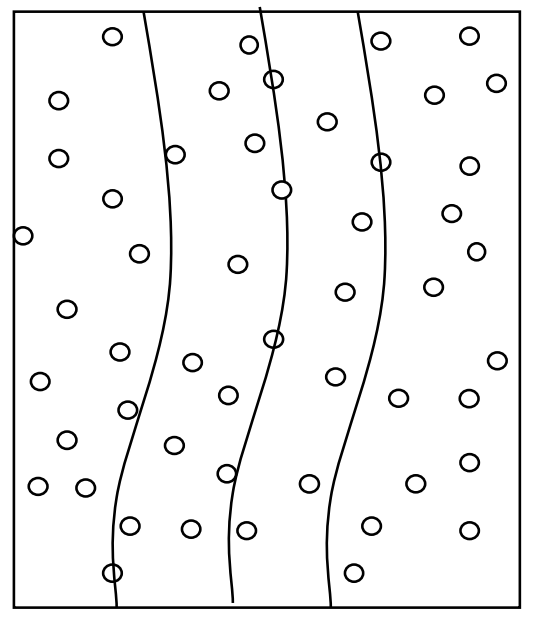

Fig. 2. Schematic of Mott-Nabarro dislocation theory

On another hand, if the solute atoms are distributed irregularly in the matrix in the form of a single atom or atomic group, the motion of dislocations in the matrix causes uniform reinforcement. MottNabarro theory [20] holds that uniform strengthening is mainly caused by the internal stress field produced by the mismatch between solute and matrix atoms. Dislocation lines can move flexibly, and the degree of bending reflects the strengths of the solute atoms. The theory indicates that the solid-solution strengthening effect is an exponential function of the solute content. Fig. 2 is a schematic that explains Mott-Nabarro theory, where the box, circles, and curves represent the matrix, solute atoms, and dislocation lines, respectively. As observed in Fig. 2, the solute atoms are uniformly and randomly distributed in the matrix. In the alloy, solute atoms are pinned in the matrix; when dislocations move and meet solute atoms, the dislocation will be hindered by the solute atomic stress field. Interaction between solute atoms and dislocations is thus generated.

Previous work has shown that alloying elements, including $\mathrm{Al}$ and $\mathrm{Zn}$, have obvious effects on the solid-solution strengthening of magnesium alloys. Al can substantially improve the room temperature strengths of magnesium alloys. The yield strengths of $\mathrm{Mg}-\mathrm{Al}$ alloys have been reported to improve with increasing aluminum content (up to 9\%) [21]. Cáceres and Rovera [22] found that the $0.2 \%$ proof strength $\left(\sigma_{\mathrm{p}}\right)$ of a $\mathrm{Mg}-\mathrm{Al}$ alloy increased linearly with the $n$th power of component $c$ after correcting for grain size strengthening effects, where $c$ is the atom concentration and $1 / 2 \leq n$ $\leq 2 / 3$. The $\sigma_{\mathrm{p}}$ of the alloy can be expressed as

$$
\sigma_{\mathrm{p}}=\sigma_{0}+k d^{-\frac{1}{2}}+m B_{n} c^{n}
$$


where $\sigma_{0}$ and $k$ are parameters determined by the polycrystalline material, $d$ is the grain size, $m$ is the Taylor orientation factor, and $B_{n}$ is the solid-solution hardening rate on the basal plane. The ability of solute atoms in the polycrystalline material to hinder dislocation motion is the main strengthening mechanism.

In addition to $\mathrm{Al}, \mathrm{Zn}$ also has a strong solid-solution strengthening effect on the magnesium alloy. When $1 \mathrm{wt} \% \mathrm{Zn}$ was added to $\mathrm{Mg}-9 \% \mathrm{Al}$ alloy (AZ91), its overall mechanical properties clearly improved [23]. In addition, the $\mathrm{ZK}$ magnesium alloy series $(\mathrm{Mg}-\mathrm{Zn}-\mathrm{Zr})$ uses $\mathrm{Zn}$ as a primary reinforcing element [24]. However, the overall mechanical properties of the alloy with added $\mathrm{Al}$ are superior to that of the added $\mathrm{Zn}$ alloy [25-26]. Although these alloying elements aid in solid-solution strengthening, they adversely affect the damping capacities of the resulting magnesium alloys.

\subsubsection{Dislocation damping in magnesium alloys}

Pure magnesium and magnesium alloys experience dislocation damping. Currently, the GranatoLücke (G-L) model is commonly used to explain the dislocation damping mechanism [27]. This model considers that both ends of the dislocation line in the crystal are strongly pinned by immobile defects such as grain boundaries, precipitation phases, or dislocation network nodes and that the intermediate portion is pinned by impurity atoms. The dislocation segment length $L_{\mathrm{N}}$ and the average length between the weak pinning points $L_{\mathrm{C}}$ are determined by these defects and impurities. A qualitative explanation of the changes to the dislocation length under influence from increasing external stress is observed in Fig. 3(a). With zero applied stress, the line $\left(L_{\mathrm{N}}\right)$ is pinned by strong pinning points (A in Fig. 3(a)). With a small amount of stress, the loops $\left(L_{\mathrm{C}}\right)$ bow out between weak pinning points and continue to bow out until the breakaway stress is reached ( $B-D$ in Fig. 3(a)). As the stress increases, the dislocation line also bows out ( $E-F$ in Fig. 3(a)), then new closed dislocation loops form ( $G$ in Fig. 3(a)). Dislocation propagation occurs according to the Frank-Read mechanism. When the stress is unloaded, the line $\left(L_{\mathrm{N}}\right)$ goes back to its original position and is pinned again.

Fig. 3(b) shows a schematic of the stress and strain corresponding to the aforementioned model. Because of differences between the loading and unloading mechanisms during Shockley partial dislocation, the slopes of the stress-strain curves in these two processes is different. Hence, the curve shows a hysteresis loop, which generates internal friction. 


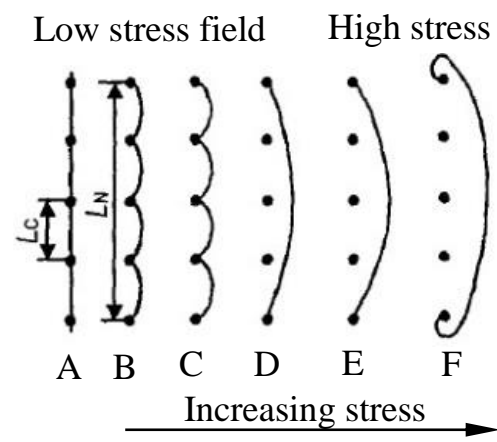

(a)

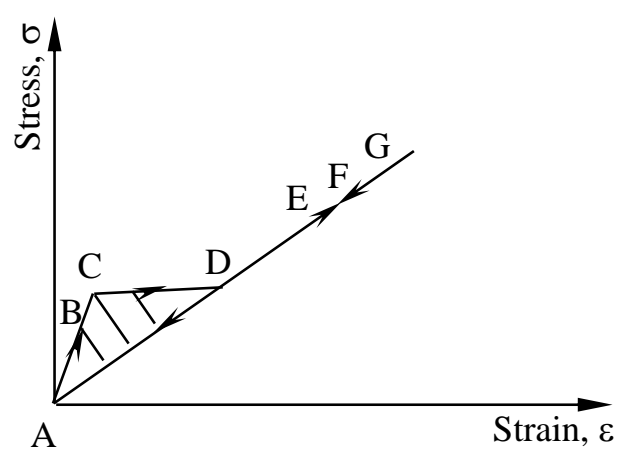

(b)

Fig. 3. Dislocation pinning internal friction model: (a) G-L dislocation pinning model and (b) a schematic of $\sigma-\varepsilon$ during dislocation unpinning and re-pinning.

Damping occurs when dislocation segments are subjected to forced damping vibrations. This resonance-type damping is both amplitude independent and frequency dependent. The staggered rear damping caused by stapling of dislocation segments is both amplitude dependent and frequency independent. The above two damping classes are expressed by Eqs. (2) and (3):

$$
\begin{gathered}
Q_{0}^{-1}=\frac{B \Lambda L^{4} \omega}{36 G b^{2}} \\
Q_{\mathrm{H}}^{-1}=\frac{C_{1}}{\varepsilon} \exp \left(-\frac{C_{2}}{\varepsilon}\right)
\end{gathered}
$$

where $Q_{0}^{-1}$ represents amplitude independent damping, $Q_{\mathrm{H}}^{-1}$ represents amplitude dependent damping, $B$ is a dislocation movement damping constant, $\Lambda$ is dislocation density, $L$ is the mean length between weak pinning points, $\omega$ is the angular frequency, $G$ is the shear modulus, $\boldsymbol{b}$ is the Burgers vector, $C_{1}$ and $C_{2}$ are physical constants, and $\varepsilon$ is the strain amplitude. The total damping of the material $\left(Q^{-1}\right)$ can be expressed by Eq. (4):

$$
Q^{-1}=Q_{0}^{-1}+Q_{\mathrm{H}}^{-1}
$$

Eq. (3) can be converted to 


$$
\operatorname{In}\left(Q_{\mathrm{H}}^{-1} \cdot \varepsilon\right)=\operatorname{In} C_{1}-\frac{C_{2}}{\varepsilon}
$$

The G-L line can be obtained from parameters $\ln \left(Q_{\mathrm{H}}^{-1} \cdot \varepsilon\right)$ and $\varepsilon$. Whether it exhibits a linear relationship is an important criterion for determining whether dislocation damping is the correct mechanism.

\subsubsection{Effect of a single solute atom on the damping capacity of a magnesium alloy}

The G-L model shows that the damping capacity of the alloy is closely related to the degree of pinning. Specifically, the damping capacity decreases with the increase of the degree of pinning. The pinning points in the crystal can be divided into two categories: weak pinning points such as solute atoms and vacancies and strong pinning points such as secondary-phase particles and grain boundaries. The stress field of the dislocation in the solid-solution interacts with that of the solute atom. Therefore, analysis of the solid-solution effect on the damping capacity is necessary. The first approach is to analyze pinning of a single solute atom to the dislocation line, wherein the degree of pinning is a function of the selected alloy atom. The second approach is to analyze the effect of the solute content on the pinning length of the dislocation line.

Cottrell proposed a simple physical model to deal with interactions between a dislocation and a single solute atom [28]. The hollow hole in the continuous medium are filled with balls of different radii, and the difference in volume between the two are considered to be the difference between the volumes of solute and solvent atoms. If this process is carried out in the dislocation stress field, the negative value of the dislocation stress field work is equal to the interaction energy. Using the stress field formula for an edge dislocation, we can find the energy of interaction between the dislocation and the solute atoms [29].

$$
\begin{gathered}
\Delta U=\frac{1}{3 \pi} \cdot \frac{1+V}{1-V} \cdot \boldsymbol{\mu} \boldsymbol{b} \cdot \Delta V \cdot \frac{\sin \theta}{r} \\
\Delta V=\frac{4}{3} \pi r_{1}^{3}-\frac{4}{3} \pi r_{2}^{3}
\end{gathered}
$$




$$
\text { Make } \delta=\frac{r_{1}-r_{2}}{r_{2}} ; r_{1}=r_{2}(1+\delta)
$$

$$
\text { Then } \Delta V \approx 4 \pi \delta \cdot r_{2}^{3}
$$

$$
\Delta U=\frac{4}{3} \cdot \frac{1+v}{1-v} \cdot \mu \boldsymbol{b} \cdot \delta \cdot r_{2}^{3} \cdot \frac{\sin \theta}{r}
$$

where $\Delta U$ is the interaction energy; $\nu$ is Poisson's ratio; $\mu$ is the shear modulus; $\boldsymbol{b}$ is the Burgers vector; $\Delta V$ is the volume difference between solute atoms and solvent atoms; $r_{1}$ and $r_{2}$ are the atomic radii of the solute and solvent atoms, respectively; $\delta$ is the mismatch degree; $r$ is the polarity in polar coordinates; and $\theta$ is the polar angle.

The results demonstrate that the pinning effect of solute atoms on dislocations is closely related and approximately proportional to the difference between the atomic radii. The greater the mismatch degree, the stronger the force that pins the solute atoms to the dislocations. The crystal structure parameters of the solute atoms and matrix $\mathrm{Mg}$ in the magnesium alloys are illustrated in Table 2. $\mathrm{Mn}, \mathrm{Al}, \mathrm{Ni}, \mathrm{Cu}$, and $\mathrm{Zn}$ have small atomic mismatches with $\mathrm{Mg}$ atoms and thus have a weak dislocation pinning effect according to the aforementioned system. However, factors other than dislocation mismatch are important to the pinning of a single atom to a dislocation. For example, $\mathrm{Y}$ has a greater atomic mismatch than $\mathrm{Zn}$ but is not as well-pinned as $\mathrm{Zn}$ at the same solute concentration (Fig. 1). The authors of previous investigations [30] have noted the difference between the moduli of the solute atoms and the matrix, which affects interactions between the dislocation and the solute atoms. The greater the difference in moduli, the stronger the interaction. Because of the smaller modulus of $\mathrm{Y}$ compared with that of $\mathrm{Zn}$, the resulting dislocation line pinning is not as good as with $\mathrm{Zn}$. In addition, the crystal structure of the alloy matrix can affect interactions between solute atoms and dislocation lines. Alloying elements with the same crystal structure easily form solid solutions. For example, $\mathrm{Zn}$ is more easily dissolved in the $\mathrm{Mg}$ matrix because they share the same crystal structure, resulting in dislocation pinning.

Table 2. Crystal parameters of alloying elements 


\begin{tabular}{ccccc}
\hline $\begin{array}{c}\text { Alloy } \\
\text { element }\end{array}$ & $\begin{array}{c}\text { Atomic radius } \\
\mathrm{nm}\end{array}$ & $\begin{array}{c}\text { Mismatch degree } \\
(|\delta|)\end{array}$ & $\begin{array}{c}\text { Modulus / } \\
\text { GPa }\end{array}$ & $\begin{array}{c}\text { Crystal } \\
\text { structure }\end{array}$ \\
\hline $\mathrm{Mg}$ & 0.172 & 0 & 45 & HCP \\
$\mathrm{Al}$ & 0.182 & 0.058 & 70 & FCC \\
$\mathrm{Mn}$ & 0.179 & 0.041 & 198 & BCC \\
$\mathrm{Zn}$ & 0.153 & 0.110 & 108 & HCP \\
$\mathrm{Y}$ & 0.227 & 0.319 & 64 & HCP \\
$\mathrm{Ca}$ & 0.223 & 0.296 & 20 & FCC \\
$\mathrm{Nd}$ & 0.264 & 0.534 & 41 & FCC \\
\hline
\end{tabular}

$\mathrm{Zn}$ has the most unfavorable damping capacity effects, consistent with the experimental results in Fig. 1. The atomic mismatch is of primary importance to the effect of a single atom on the damping capacity of a magnesium alloy. The greater the mismatch, the greater the pinning force on the dislocation. Moreover, modulus also influences the pinning force. A larger modulus difference with magnesium results in stronger pinning forces. Finally, the pinning of nonpacked hexagonal alloying elements in magnesium is typically weak.

\section{Conclusions}

(1) Solid-solution strengthening is not conducive to improving alloy damping capacities. Thus, to prepare high-damping magnesium alloys, alloying elements with poor solid solubilities should be selected. The effect of solid solubility on the damping capacity can be considered from two perspectives: (i) the effect of single solid-solution atoms on the damping capacities of the alloy and (ii) the effect of solubility on the damping capacities of the alloy.

(2) The degree of atomic mismatch is critical to the influence of single atoms on the damping capacity of a magnesium alloy. The greater the mismatch, the greater the pinning force on the dislocation. When the difference between moduli is larger, the pinning force is stronger. Moreover, crystal structure factors must be considered because the pinning of nonpacked hexagonal alloying elements in magnesium is typically weaker. 
(3) Fine-grain strengthening is a good way to develop high-strength, high-damping magnesium alloys if it ensures better mobility of dislocation lines inside the grains. Some alloying elements that aid the damping capacities of magnesium alloys can also achieve improved fine-grain strengthening effects.

\section{Acknowledgements}

This work was financially supported by the National Natural Science Foundation of China (Nos. 51361010 and 51665012) and the Jiangxi Province Science Fund for Distinguished Young Scholars (Nos. 20171BCB23061 and 2018ACB21020).

\section{References}

[1] Z.L. Zhang, X.Q. Zeng, and W.J. Ding, The influence of heat treatment on damping response of AZ91D magnesium alloy, Mater. Sci. Eng. A, 392(2005), No. 1-2, p. 150.

[2] R. Ma, X.P. Dong, B.S. Yan, S.Q. Chen, Z.B. Li, Z. Pan, H.J. Ling, and Z.T. Fan, Mechanical and damping properties of thermal treated $\mathrm{Mg}-\mathrm{Zn}-\mathrm{Y}-\mathrm{Zr}$ alloys reinforced with quasicrystal phase, Mater. Sci. Eng. A, 602(2014), p. 11.

[3] W.Z. Huang, H.J. Luo, Y.L. Mu, H. Lin, and H. Du, Low-frequency damping behavior of closed-cell Mg alloy foams reinforced with SiC particles, Int. J. Miner. Metall. Mater., 24(2017), No. 6, p. 701.

[4] R. González-Martínez, J. Göken, D. Letzig, K. Steinhoff, and K.U. Kainer, Influence of aging on damping of the magnesium-aluminium-zinc series, J. Alloys Compd., 437(2007), No. 1, p. 127.

[5] S.Q. Feng, W.Y. Zhang, Y.H. Zhang, J.Y. Guan, and Y.C. Xu, Microstructure, mechanical properties and damping capacity of heat-treated $\mathrm{Mg}-\mathrm{Zn}-\mathrm{Y}-\mathrm{Nd}-\mathrm{Zr}$ alloy, Mater. Sci. Eng. A, 609(2014), p. 283.

[6] A. Granato and K. Lücke, Theory of mechanical damping due to dislocations, J. Appl. Phys., 27(1956), p. 583.

[7] A. Granato and K. Lücke, Application of dislocation theory to internal friction phenomena at high frequencies, J. Appl. Phys., 27(1956), p. 789.

[8] T. Gancarz, J. Jourdan, W. Gasior, and H. Henein, Physicochemical properties of Al, Al-Mg and Al-Mg-Zn alloys, J. Mol. Liq., 249(2018), p. 471.

[9] S.S.V. Tatiparti and F. Ebrahimi, Nanostructure stabilization in electrodeposited Al-Mg dendrites, J. Alloys Compd., 694(2017), p. 634. 
[10]D. Nagarajan, X. Ren, and C.H. Cáceres, Anelastic behavior of $\mathrm{Mg}-\mathrm{Al}$ and $\mathrm{Mg}-\mathrm{Zn}$ solid solutions, Mater. Sci. Eng. A, 696(2017), p. 387.

[11] S. Zhu, Z.H. Li, L.Z. Yan, X.W. Li, S.H. Huang, H.W. Yan, Y.G. Zhang, and B.Q. Xiong, Effects of $\mathrm{Zn}$ addition on the age hardening behavior and precipitation evolution of an $\mathrm{Al}-\mathrm{Mg}-$ Si-Cu alloy, Mater. Charact., 145(2018), p. 258.

[12] T. Motoyama, H. Watanabe, N. Ikeo, and T. Mukai, Mechanical and damping properties of equal channel angular extrusion-processed Mg-Ca alloys, Mater. Lett., 201(2017), p. 145.

[13] L.B. Ren, G.F. Quan, Y.G. Xu, D.D. Yin, J.W. Lu, and J.T. Dang, Effect of heat treatment and pre-deformation on damping capacity of cast Mg-Y binary alloys, J. Alloys Compd., 699(2017), p. 976.

[14] H.X. Li, S.K. Qin, Y.Z. Ma, J. Wang, Y.J. Liu, and J.S. Zhang, Effects of Zn content on the microstructure and the mechanical and corrosion properties of as-cast low-alloyed $\mathrm{Mg}-\mathrm{Zn}-\mathrm{Ca}$ alloys, Int. J. Miner. Metall. Mater, 25(2018), No. 7, p. 800.

[15] A. Puškár. Internal Friction of Materials, Cambridge International Science Publishing, Cambridge, 2001, p. 386.

[16] Y.J. Cui, Y.P. Li, S.H. Sun, H.K. Bian, H. Huang, Z.C. Wang, Y. Koizumi, and A. Chiba, Enhanced damping capacity of magnesium alloys by tensile twin boundaries, Scripta Mater., 101(2015), p.8.

[17] L.H. Liao, X.Q. Zhang, H.W. Wang, X.F. Li, and N.H. Ma, The characteristic of damping peak in Mg-9Al-Si Alloys, J. Alloys Compd., 429(2007), No. 1, p. 163.

[18] L. Gao, R.S. Chen, and E.H. Han, Effects of rare-earth elements Gd and Y on the solid solution strengthening of Mg alloys, J. Alloys Compd., 481(2009), No. 1-2, p. 379.

[19] Z.R. Liu and D.Y. Li, The electronic origin of strengthening and ductilizing magnesium by solid solutes, Acta Mater., 89(2015), p. 225.

[20] E.A. Protopopov, A.I. Val'ter, A.A. Protopopov, and P.I. Malenko, Regression relations for estimating the mechanical properties of steels subjected to solid-solution hardening, Russ. Metall., 2015(2015), No. 7, p. 565.

[21] Z.T. Li, X.D. Zhang, M.Y. Zheng, X.G. Qiao, K. Wu, C. Xu, and S. Kamado, Effect of Ca/Al ratio on microstructure and mechanical properties of $\mathrm{Mg}-\mathrm{Al}-\mathrm{Ca}-\mathrm{Mn}$ alloys, Mater. Sci. Eng. A, 682(2017), p. 423.

[22] C.H. Cáceres and D.M. Rovera, Solid solution strengthening in concentrated $\mathrm{Mg}-\mathrm{Al}$ alloys, $J$. Light Met., 1(2001), No. 3, p. 151.

[23] K.M. Asl, A. Masoudi, and F. Khomamizadeh, The effect of different rare earth elements content on microstructure, mechanical and wear behavior of $\mathrm{Mg}-\mathrm{Al}-\mathrm{Zn}$ alloy, Mater. Sci. Eng. A, 527(2010), No. 7-8, p. 2027.

[24] T. Bhattacharjee, C.L. Mendis, T.T. Sasaki, T. Ohkubo, and K. Hono, Effect of Zr addition on 
the precipitation in Mg-Zn-based alloy, Scripta Mater., 67(2012), No. 12, p. 967.

[25] X.S. Huang, K. Suzuki, A. Watazu, I. Shigematsu, and N. Saito, Mechanical properties of MgAl-Zn alloy with a tilted basal texture obtained by differential speed rolling, Mater. Sci. Eng. A, 488(2008), No. 1-2, p. 214.

[26] J.J. He, B. Jiang, H.M. Xie, Z.T. Jiang, B. Liu, and F.S. Pan, Improved tension-compression performance of Mg-Al-Zn alloy processed by co-extrusion, Mater. Sci. Eng. A, 675(2016), p. 76.

[27] H. Feng, H.P. Liu, H. Cao, Y. Yang, Y.C. Xu, and J.Y. Guan, Effect of precipitates on mechanical and damping properties of Mg-Zn-Y-Nd alloys, Mater. Sci. Eng. A, 639(2015), p. 1.

[28] E. Pink and A. Grinberg, Stress drops in serrated flow curves of A15Mg, Acta Metall., 30(1982), No. 12, p. 2153.

[29] J.A. Yasi, L.G. Hector Jr, and D.R. Trinkle, First-principles data for solid-solution strengthening of magnesium: From geometry and chemistry to properties, Acta Mater, 58(2010), No. 17, p. 5704.

[30] R.L. Fleisgher, Solution hardening, Acta Metall., 9(1961), No. 11, p. 996. 